\title{
The nature of the creative workforce
}

\author{
Adriana Bujor $^{1 *}$, Silvia Avasilcai ${ }^{2}$,Lidia Alexa ${ }^{3}$ \\ 1“Gheorghe Asachi” Technical University of Iasi, adbujor@gmail.com, Romania \\ 2"Gheorghe Asachi” Technical University of Iasi, silvia.avasilcai@gmail.com, Romania \\ 3"Gheorghe Asachi” Technical University of Iasi, lidia.alexa@tuiasi.ro, Romania
}

\begin{abstract}
Considering the fact that creative, creativity, co-creation are so very used terms in the last years, that creative industries and entrepreneurship in creative industries are the subject to many conferences, symposiums, courses, curricula, etc., discussions on creative economy is a subject of current interest, as well. To better understand creative economy, one must understand the nature of the creative workforce. The aim of this paper is to identify the nature of creative workforce. The foreseen result is to highlight the differences between creative industries and creative jobs, starting from the identified nature of the creative industries
\end{abstract}

\section{Introduction}

If in general terms, almost all industries use / contain at least an element of creativity, creative industries differ in that the value they offer to their customers / consumers is determined / provided by the creativity only, according to UNCTAD, and UNDP [1]. Basically entries are of a cultural / creative dimension, even if the results have a functional size.

Having as standard the definition of the creative industries offered by DCMS (Department for Culture, Media and Sport), T. Flew [2], the creative / cultural dimension inputs occur only due to the individual talent and skills, and the outputs are innovative products and services, that needs to be protected by copyright (intellectual property).

If we consider, as an example, a furniture design project, the creative dimension is given by the level of which that designer uses his / her creativity, individual talent and skills in order to span all the needed resources to create that piece of furniture that usually has a functional size. But what makes them to qualify as industries, namely creative industries, it is their potential to generate / make profit, to provide a way of living and the possibility to create and develop a business, capable of generating (new) workforce, (new) jobs.

The project's functional size is determined by the clients' feedback, the last step of the design process, which analyzes the degree of their requirements fulfillment.

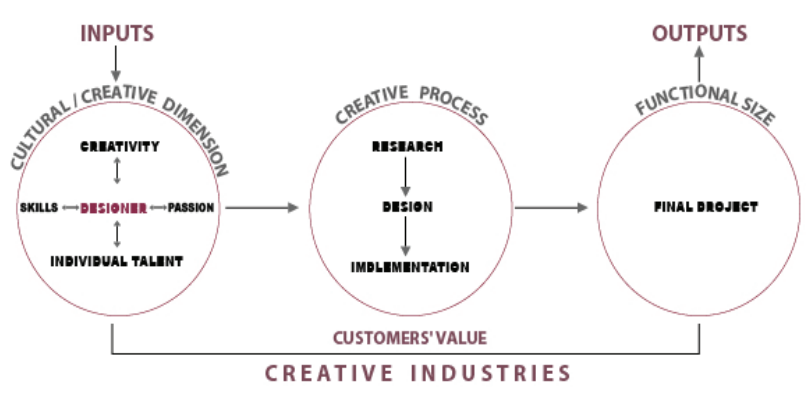

Fig. 1. Inputs and outputs in creative industries.

Even though most businesses that are part of the creative industries are often micro, small or medium sized enterprises that have started mainly on local markets, most of them can develop into strong economic clusters (creative clusters) capable of inducing economic growth.

\section{Creative industries and the work foundation model}

During the researches done so far on creative industries in Romania many suspicions and questions have arisen. There are still doubts that culture's outputs can develop into profit, and, even more, into businesses, no matter the size.

For this reason, for those working in cultural domains or connected with cultural activities, the Concentric Circles Model proposed by the Work Foundation suit best.

Unlike the model proposed by NESTA (National Endowment for Science, Technology and the Arts) [3], the Work Foundation [4] has made a distinction between creative contents and industries that produce and distribute them, according to the expressive value of the

Corresponding author: adbujor@gmail.com 
creative products and services.

The expressive value term is defined as "any dimension (in ideas), which, in its broadest sense, extends the cultural meaning and understanding", according to the Work Foundation [4]. The term incorporates elements such as:

1) aesthetic value;

2) spiritual value;

3) historical value;

4) symbolic value;

5) authentic value.

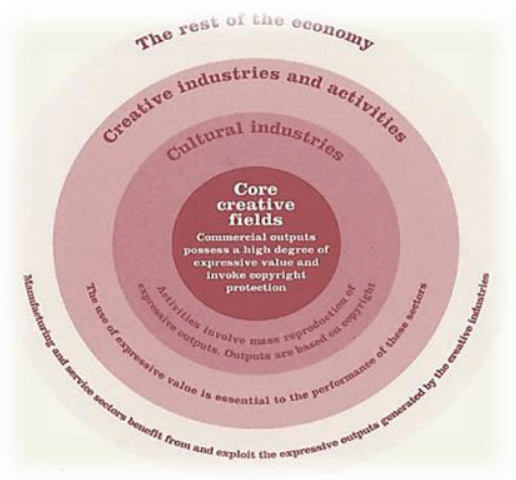

Fig. 2. The Concentric Circles Model proposed by the Work Foundation [4].

Expressive value is used to differentiate creation and performing arts of commercial media, precisely because of the aesthetic value and the meaning that the first two have, and to justify the investment that the public make in them.

\subsection{The nature of creative industries}

Once with the appearance of the creative industries, the creative economy term has appeared and aroused much interest. In order to better understand the term of creative economy, one must understand which the nature of the creative workforce is.

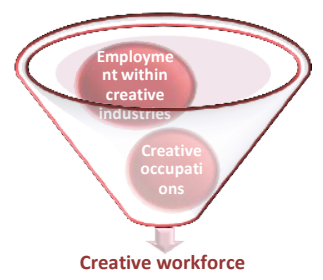

Fig. 3. The nature of the creative workforce.

As shown in fig. 3, creative workforce does not strictly refer to the workforce within creative industries. It actually represents the combination of creative occupations and employment within creative industries.

Another question that arose during the research on creative industries and their classification, especially in Romania, referred to the level of understanding the difference between creative industries and creative workforce / creative jobs.

Starting from a question like: "Why the automotive industry is not a creative industry?" a better differentiation can be offered, giving in the same time a clear explanation on a creative industries' sector, with related jobs, and a creative job that can be found in any type of industry.

For this, Queensland University of Technology Center of Excellence for Creative Industries and Innovation created the Creative Trident, representing a useful tool / methodology to show the different values of the creative jobs and the creative sectors / segments. According to this trident described by Creative Industries Innovation Centre [5], there are:

6) specialist creatives;

7) support workers;

8) embedded workers.

The specialist creative is the one that actually works within creative industries, being creatively occupied (doing creative jobs), in contrast to the support worker, that even though he or she works as well within creative industries, does not do creative jobs. The last type of worker, the embedded one, is creatively occupied, as the first type, but does not work within creative industries.

Table 1. The Creative Trident

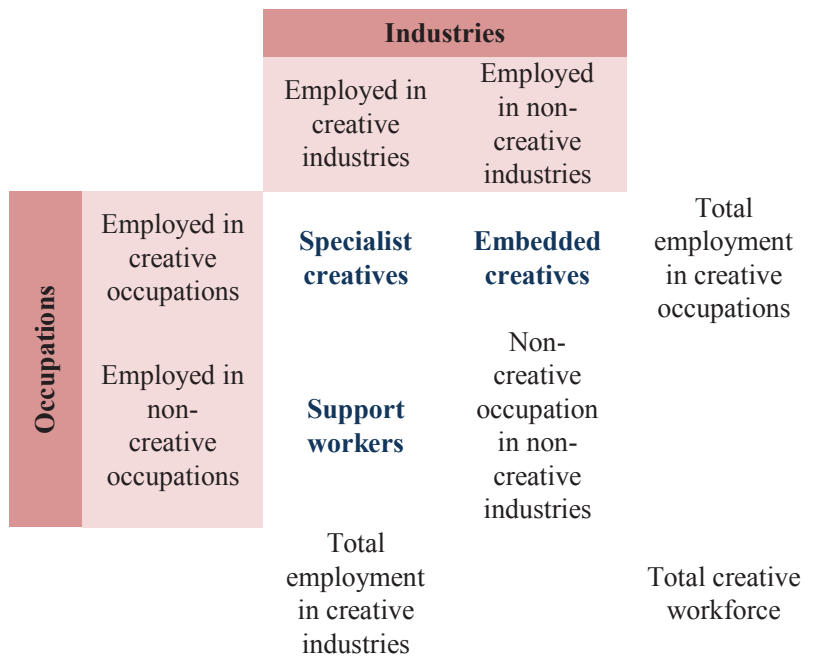

According to the creative trident, the best answer / explanation to the previous question is that within an automotive industry embedded workers are found. This type of industry has not been classified as a creative industry, but within it there are many creative jobs, among non-creative others, such as the (product) designer within an automotive industry, or a graphic designer in different non-creative industries, so on.

What can be added to this trident, is another category of workforce that lately has arisen. This category is formed of so called prosumers that can be considered a creative workforce, with certain limitations.

Defined as one "who blurs the distinction between a consumer and a producer", as stated by W. Gerhardt [6],

Corresponding author: adbujor@gmail.com 
a prosumer can be considered a type of workforce as a prosumer can participate to the co-creation of goods, or the development of different services for a company.

The main difference among all these types of workforce is that a consumer involved in a company's co-creation process (another way to define a prosumer) becomes a form of free workforce, raising many controversies among labor specialists, and it can be found in any occupations and in any industries from the trident.

The "job markets" for a prosumer, as emphasized by A. Bujor, and S. Avasilcai [7], are represented by:

1) traditional consumer channels, such as advertising and mail;

2) nontraditional channels, such as: e-mail, online sites (Google);

3) business-to-business channels, such as: industry site advertising, and trade publications.

Table 2. The Creative Trident and Prosumer's place within it

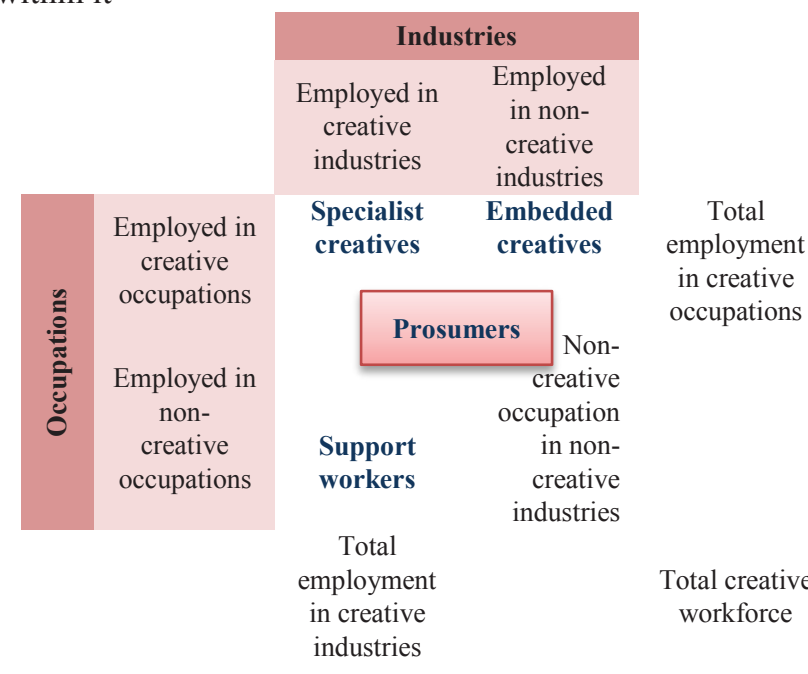

\section{The creative workforce in Europe-28 (EU-28): a comparative analysis}

The economic value of creative industries has been increasingly recognized by now, all over the world, despite the fact that $80 \%$ of the businesses in the creative industries fields consist of SMEs (with many sole traders or with only no more than three employees) or microenterprises with just few employees, as well.

\subsection{Creative workforce in Europe}

If in 2008, according to Terraconsult, the creative employment in UK and Germany was of 2.7 million, in France of 1.7 million, in Italy of 1.4 million and in Spain of 1.2 million, the percentage of jobs in creative industries was as it follows: $9.2 \%$ in UK, $6.2 \%$ in France, $6.9 \%$ in Germany, $6.1 \%$ in Italy, and $5.9 \%$ in Spain.

From all sectors of creative industries, the statistical analysis has shown that in Fashion can be found the most workers employed with $31.41 \%$ of total employees, followed by Design with $20.12 \%$, Architecture with $10.74 \%$, and Book\&Press with $9.89 \%$ of total employees, as presented by Hogeschool vor de Kunsten Utrecht, [8].

Many creative entrepreneurs are also employed in other sectors of the economy, contributing this way to the development of the creative capacity of non-creative industries. They represent the embedded creatives from the trident.

According to NESTA, the 2011-2013 average of all creative industries EU-28's employment was of $11,218,000$, accounting for 5,21\% of the EU workforce, as emphasized by M. Nathan, A. Pratt, and A. RinconAznar [9].

\subsection{Creative Trident for Europe-28: a comparative Analysis}

The data found for this comparative analysis did not allow comparing all 28 European countries, between 2011-2013, due to the absence of the 4 digit occupational resolution, in the following countries: Bulgaria, Cyprus, Denmark, Greece, Italy, Portugal, Latvia and Spain, also Belgium and Germany but only for 2011. Thus, due to the above and wishing to obtain accurate information and data, the comparative analysis has been limited to only 18 European countries, even though general data on workforce in countries like Denmark, Germany, Portugal and Spain are relevant at European level and not only.

Table 3. Creative Tridents for Europe-28 (2011-2013)

\begin{tabular}{|l|c|l|l|}
\hline & $\begin{array}{c}\text { Creative } \\
\text { industries }\end{array}$ & $\begin{array}{c}\text { Non-creative } \\
\text { industries }\end{array}$ & $\begin{array}{c}\text { Creative } \\
\text { industries }\end{array}$ \\
\hline $\begin{array}{l}\text { Creative } \\
\text { occupations }\end{array}$ & $2,921,000$ & $3,273,000$ & $6,194,000$ \\
$\begin{array}{l}\text { Non-creative } \\
\text { occupations }\end{array}$ & $6,094,000$ & $150,046,000$ & $156,140,000$ \\
$\begin{array}{l}\text { All } \\
\text { occupations }\end{array}$ & $11,387,000$ & $206,178,000$ & $217,565,000$ \\
\hline
\end{tabular}

Of the $18^{\text {th }}$ EU member states for which we consider the creative economy, U.K., registering so far the larger cultural and creative industries in Europe, is definitely the leader in creative specialists $(816,000$ working in both creative occupations and creative industries), followed by France, at a considerable distance $(264,000)$, and Netherlands $(190,000)$. Romania ranks $11^{\text {th }}$ place out of 18 (35,000), Luxembourg being the last ranked $(1,000)$.

As for embedded creatives (working in both creative occupations and non-creative industries), U.K. has the largest employment $(570,000)$, followed again by France $(449,000)$ and Poland this time $(278,000)$. Romania ranks $6^{\text {th }}$ place out of $18(122,000)$, Luxembourg being once again the last ranked $(1,000)$.

The top three of support workers/non-specialists creative (employed in both non-creative occupations and creative industries) is as it follows: U.K. $(1,405,000)$, France $(1,169,000)$, and Poland $(381,000)$. This time

Corresponding author: adbujor@gmail.com 
Romania ranks $10^{\text {th }}(109,000)$, and Malta ends the top (5000).

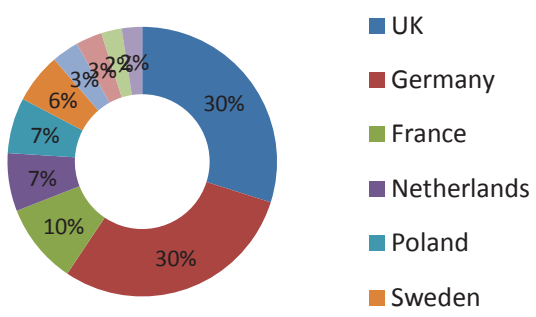

Fig.4. Top 10 creative specialists working in both creative occupations and creative industries

Poland once again finds itself in top three, even though to a considerable distance $(8,923,000)$, while Malta closes once again the list $(158,000)$. For this category, Romania manages this time to rank $4^{\text {th }}$ out of 18, employing considerable less than top three.

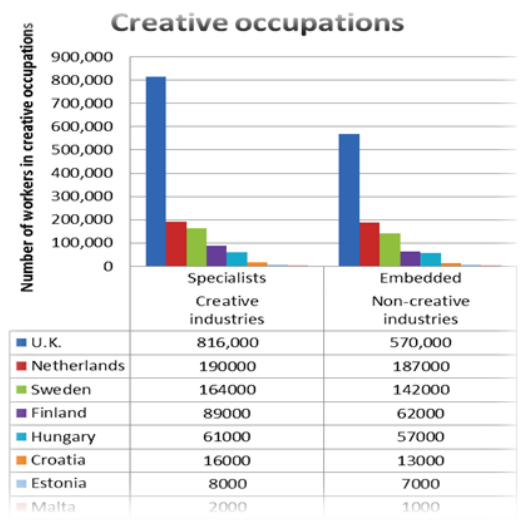

Fig.5. Creative workers from creative industries vs. creative workers from non-creative industries

What can be concluded from this analysis is that all EU countries experienced, during the years, great growth in each creative economy workforce, especially in specialist creatives and embedded creatives, as the importance of creatives' presence proved to be of great help in both creative and non-creative industries.

Another conclusion that emerges from this analysis is that there are countries that managed to employ more creative workers inside their creative industries than outside: the U.K. $(816,000$ vs. 570,000), Netherlands (190,000 vs. 187,000), Sweden (164,000 vs. 142,000), Finland (89,000 vs. 62,000), Hungary (61,000 vs. $57,000)$, Croatia (16,000 vs. 13,000), Estonia (8000 vs. 7000), Malta (2000 vs. 1000). In Luxembourg the number of creative workers employed in creative industries is similar to those employed in non-creative industries (1000).

\section{Conclusion}

Creative industries are made up of different sectors whose outputs are also different, of functional size, even though their institutional organizations and employment patterns have many things in common. What is sure is that the inputs are of cultural / creative dimension, based on individual talent, passion, skills and craftsmanship.

Creative workforce does not refer only to the workforce within creative industries, but to the workforce whose core is creativity. According to the Creative Trident there are: specialist creatives (employed in creative occupations within creative industries), support creatives (employed in non-creative occupations within creative industries), and support creatives (employed in creative occupations within non-creative industries). To this trident, prosumers can also be added as a creative workforce, if we take into consideration the way they are engaged in a company's co-creation process.

Taking into account all the data, European creative economies manage to exceed the best they can, in their ways. At European level, U.K. is the leader, registering so far the larger cultural and creative industries.

This research was undertaken within the framework of the National Research Program PN II, financed by MEN UEFISCDI, project PN-II-PT-PCCA-2013-4-1811.

\section{References}

11] UNCTAD, UNDP, Creative Economy: A Feasible Development Option, 2010 Report.

[2] T. Flew, The Creative Industries. Culture and Policy, SAGE Publications Ltd, 2012.

[3] NESTA, Creating Growth: How the UK Can Develop World Class Creative Business, London, 2006.

[4] The Work Foundation, Staying ahead: the economic performance of the UK's creative industries, Department for Culture, Media and Sport, 2007.

[5] Creative Industries Innovation Centre, Valuing Australia's Creative Industries. Final report, University of Technology, Sydney, December 2013.

[6] W. Gerhardt, Prosumers: A New Growth Opportunity, Cisco Internet Business Solutions Group (IBSG), March 2008, Retrieved from CISCO Web Site: http://www.cisco.com/c/dam/en_us/about/ac79/docs /wp/Prosumer_VS2_POV_0404_FINAL.pdf.

[7] A. Bujor, and S. Avasilcai, "Co-creation in Romanian consumer goods industry", Annals of the Oradea University, Fascicle of Management and Technological Engineering, Issue \#2, August 2016.

[8] HKU, The Enrepreneurial Dimension of the Cultural and Creative Industries, Hogeschool vor de Kunsten Utrecht, 2010.

1. M. Nathan, A. Pratt, and A. Rincon-Aznar, Creative Economy Eomployment in the EU and the UK. A comparative Analysis, NESTA, London, December 2015.

\footnotetext{
Corresponding author: adbujor@gmail.com
} 